\title{
Evaluation of mycobiota and mycotoxins in moist and natural pet foods sold in Brazil
}

\author{
Erika Figueiredo Pereira ${ }^{1}$, Gabriela Garcia Mozart", Luciana da Silva Souza Teixeira ${ }^{1}$, Marcos Aronovich², \\ Eliane Rodrigues ${ }^{2}$, Luiz Antonio Moura Keller ${ }^{1}$
}

\begin{abstract}
This study evaluated the mycobiota and mycotoxins quality of moist and natural foods for dogs and cats sold in Brazil. Three lots of 12 samples were collected, 4 corresponding to diets categorized as economic, 2 for each species, 6 as premium, 2 feline and 4 canine, and 2 diets as natural, 1 for each species. Only 1 feline premium brand evaluated did not extrapolate the limit of $10^{3} \mathrm{CFU} / \mathrm{g}$ for molds and yeasts, as recommended by Brazilian National Health Surveillance Agency (ANVISA) for animal products foods. In addition to the high counts, it was also found a wide variety of fungi. Aflatoxins, Fumonisin, Zearalenone and Deoxynivalenol were evaluated. The majority of samples were contaminated by at least one mycotoxin, 83,3\%. Detected levels of Deoxynivalenol, Zearalenone, and Fumonisin were much below Food and Drug Administration (FDA) and EU recommendations and Aflatoxins was not detected in the samples. Indices found may represent risks to the pet's health.
\end{abstract}

Keywords: contamination; diet; mold; dogs; cats.

\section{Introduction}

According to the Brazilian Association of the Pet Products Industry (ABINPET), the National Pet Market, which $73.9 \%$ corresponds to the pet food industry, registered revenues of $\mathrm{R} \$$ 20.3 billion in 2018. In addition, Brazil occupies the 2th place in the world`s pet market (ABINPET, 2019a).

Usually, the classification for commercial pet foods is based on the moisture content, which presents the following categories: dry, semi-moist and moist foods. However, in the last years, a new variety of pet foods has been developed; natural and organic foods (CASE et al., 2011). Tracking these dietary patterns of pet food, allow not only to evaluate the product quality, but also verify the possibility that these diets may have influence in animal's health.

Mycotoxins contaminate several grains worldwide, and their presence in pet food has been a health hazard threat to companion animals. The mycotoxin presence in pet food is related to the fungal growth and therefore temperature and moisture of the product. The pet food industry faces several challenges related to fungi contamination such as storage conditions, conjugated mycotoxins, grain processing and economic losses. Mycotoxins have been found in final products and raw products of pet food around the globe. And its presence may cause several food poisonings outbreaks and acute mycotoxicosis. (LEUNG; DÍAZ-LLANO; SMITH, 2006). The objective of this study was to evaluate the mycobiota and mycotoxin contamination of commercial moist foods and natural foods, for dogs and cats, sold in the state of Rio de Janeiro, with national distribution.

\section{Materials and Methods}

Three lots of 12 samples were collected, with quarterly separation, totaling 36 samples evaluated. From this total, 4 correspond to foods categorized as economic, 2 for each species (canine and feline), 6 as premium, 2 canine and 4 feline, and 2 foods as natural, 1 for each species. All samples were obtained from commercial establishments in the state of Rio de Janeiro, Brazil. A 25 grams aliquot of each sample was taken for the microbiological analysis.

Three dilutions (10-1; 10-2;10-3) were seeded in culture medium and total fungal counts of samples were performed on to three different culture media: dichloran rose bengal chloramphenicol agar (DRBC), a general medium used for estimating total culturable mycobiota (ABARCA et al. 1994); dichloran 18\% glycerol agar (DG18), a low Aw medium that favor's xerophilic fungi development (Pitt; Hocking 1997); and Nash \& Snyder agar (NS), a selective medium for Fusarium spp. counts (Nelson et al., 1983). Fungal species were identified according to Klich (2002), Nelson et al. (1983), Samson et al. (2004), and Frisvad and Samson (2004).

Samples were extracted in duplicate based on the methodology described in the AOAC (2019). Sample evaluation used commercial immunofluorimetric kits for Aflatoxins (AFs), Fumonisin (FBs), Zearalenone (ZEN) and Deoxynivalenol (DON) following manufacturer's instructions (Vicam®, MA, USA). Quantification and analysis were performed using a VICAM尺 Series-4EX fluorimeter (Vicam $®$, MA, USA). The standards $(5 \mathrm{mg})$ were purchased from Sigma (St. Louis, MO, USA). The limits of detection (LOD) and quantification (LOQ) were found by adding

\footnotetext{
${ }^{1}$ Faculdade de Veterinária, Universidade Federal Fluminense (UFF). Avenida Almirante Ary Parreiras, 503, Vital Brazil/Santa Rosa, Niterói - RJ, Brazil. 24230-340. E-mail: luiz_keller@id.uff.br

${ }^{2}$ Empresa de Pesquisa Agropecuária do Estado do Rio de Janeiro (PESAGRO-RJ). Alameda São Boaventura, 770, Fonseca, Niterói - RJ, Brazil. $24120-191$.
} 
decreasing concentrations of standard solution and subjected to extraction and quantification, repeatability $(n=5, R S D<$ 15\%). External standards for comparison (DON, FB1, ZEA and AFs), were calibrated according to the methodology described in the manual of official methods of analysis (AOAC, 2019). The detection limits were established (LOD) and quantitation (LOQ) of all evaluated toxins, in certain specific techniques. The LOD for AFs was 5,0 ppb, FB1 was 750 ppb, DON was 950 ppb and ZEA was $800 \mathrm{ppb}$. The LOQ for AFs was $50,0 \mathrm{ppb}$, FB1 was $1350 \mathrm{ppb}$, DON was $1550 \mathrm{ppb}$ and ZEA was 1800 ppb. Statistical analysis of the data was done by a two-way analysis of variance (ANOVA) used to compare the means in GraphPad Prism@ (AGRESTI, 2002).

\section{Results and Discussion}

The contaminating microbial load of yeasts and molds is shown in Table 1.

Table 1: Average and Standard Deviation of Microbiological Counts of Yeast and Mold in Samples of Feline and Canine Moist and Natural Foods in Log of Colony Forming Unit Per Gram (Log CFU/g; n=36).

\begin{tabular}{cc}
\hline Samples & Microbial load (Log CFU/g) \\
\cline { 2 - 2 } & Yeasts and Molds \\
\hline Feline Economic Brand 1 & $6,73 \pm 6,83$ \\
Feline Economic Brand 2 & $6,23 \pm 6,21$ \\
Feline Premium Brand 1 & $6,48 \pm 6,63$ \\
Feline Premium Brand 2 & $4,86 \pm 4,79$ \\
Feline Premium Brand 3 & $6,41 \pm 6,54$ \\
Feline Premium Brand 4 & $6,11 \pm 5,75$ \\
Feline Natural & $6,72 \pm 6,84$ \\
Canine Economic Brand 2 & $5,42 \pm 5,55$ \\
Canine Premium Brand 1 & $5,34 \pm 5,32$ \\
Canine Premium Brand 2 & $5,43 \pm 5,37$
\end{tabular}

Canine Natural

$6,13 \pm 6,27$

Note. Values represent the average of microbial load by colony forming units per gram of 3 different lots collected during the study period. $P>0.05$.

Only 1 feline premium brand of all pet foods evaluated did not extrapolated the limit of $10^{3} \mathrm{CFU} / \mathrm{g}$ for molds and yeasts (ABINPET, 2019b). In addition to the high counts, it was also found a wide variety of fungi. Were isolated the genus Alternaria, Aspergillus, Cladosporium, Fusarium and Penicillium. Among the Aspergillus genus was found the species $A$. flavus, $A$. fumigatus, A. ochraceus,

A. oryzae, A. parasiticus and A. niger, among the Penicillium genus, species $P$. citrinum and $P$. citreonigrum, and the Fusarium species and $F$. verticillioides and $F$. chlamydosporum. The majority of samples were contaminated by at least one mycotoxin, $83,3 \%$ (10/12). The study indicates the Fusarium spp. mycotoxins
DON ( $\leq 945 \mathrm{ppb})$, ZEN ( $\leq 800 \mathrm{ppb})$ and FB $(\leq 750 \mathrm{ppb})$ was the contaminants most prevalent and Aflatoxins was not detected in the samples. But all samples are below the LOQ of techniques. These results are in accordance with Maia and Siqueira (2002) and Campos et.al. (2008), who found low incidence rate of Aflatoxin contamination in Brazilian dog and cat food.

Pet food production manufacturers mainly apply high heating processes, moist foods undergo a commercial sterilization, while natural foods do not undergo this type of processing, contain predominantly fresh ingredients, and therefore require greater care during the food handling. The high temperature is the most relevant influence in microorganism contaminant reduction, however, the effectiveness of these processes depends on conditions used, like temperature, duration of the process or humidity (WITASZAK et al., 2020).

These samples contain significant toxigenic mycobiota contaminants, as Fusarium spp. and Aspergillus spp. Some of those strains are able in mycotoxins production. Detected levels of DON, ZEN, and FBs were much below Food and Drug Administration (FDA) and EU recommendations but in this particular case it does not guarantee safety, there are no quality control parameters for these microorganisms in the Brazilian legislation at the moment. The Brazilian pet foods industries are subject only to a recommendation from ABINPET (2019b), an unofficial body, which is based on what is defined by European Union (EU) Regulation No. 142 of 2011, that is not mandatory in Brazil. The presence of fungi can become a health hazard of animals causing infection and toxinfection since some strains may produce mycotoxins. In dogs and cats, the effects of mycotoxins are severe and can lead to death, loss of nutrients, altered organoleptic properties and reduced validity of the pet food (CAMPOS, 2007). Our results were in accordance with the data obtained during international research on mycotoxins in feed (WITASZAK et al., 2020).

These samples contain significant toxigenic mycobiota contaminants, such as Fusarium spp. and Aspergillus spp. Some of those strains are able in mycotoxins production. Detected levels of DON, ZEN, and FBs were much below Food and Drug Administration (FDA) and EU recommendations and Aflatoxins was not detected in the samples, but in this particular case it does not guarantee safety. This suggests that the issue also covers other pet food products and, hence, research should be extended to include other types of pet food.

\section{Conclusions}

Most pet foods analyzed were not in accordance with the fungal parameters suggested by ABINPET. The ingestion of pet food contaminated by fungi and its metabolites may negatively affect the health of pets, however, the samples had overall acceptable mycotoxicological quality even though the Brazilian legislation regarding the microbiological control of animal feed does not determine accurate limits of fungal and mycotoxins contamination. Further research of the quality of pet food in the Brazilian market and the implementation of fungi and mycotoxin contamination legislation is advised in order to protect the companion animals from the harmful effects of those contaminations. 


\section{References}

ABARCA M.L., BRAGULAT M.R., CASTELLÁ G., CABANES F,J. Mycoflora and aflatoxin-producing strains in animal mixed feeds. Journal of Food Protection 57: 256-258, 1994.

ASSOCIATION OF OFFICIAL ANALYTICAL CHEMISTRY AOAC. Official methods of analysis of aoac internacional. 21.ed. Arlington: AOAC International, 2019. 3390 p.

ASSOCIAÇÃO BRASILEIRA DA INDÚSTRIA DE PRODUTOS PARA ANIMAIS DE ESTIMAÇÃO - ABINPET. Mercado pet Brasil. 2019a. Disponível em: <http://abinpet.org.br/wp- content/ uploads/2019/10/abinpet_folder_2019_draft5.pdf>. Acesso em: 22/04/2021.

\section{ASSOCIAÇÃO BRASILEIRA DA INDÚSTRIA DE PRODUTOS} PARA ANIMAIS DE ESTIMAÇÃO - ABINPET. Manual pet food Brasil. 10.ed. 2019b. Disponível em: <http://abinpet.org.br/wpcontent/uploads/2020/05/manual_pet_food_ed10_completo_ digital.pdf>. Acesso em: 22/04/2021.

AGRESTI, A.; Categorical data analysis. 2.ed. New York: John Wiley \& Sons, 2002. 699 p.

BRASIL. Ministério da Agricultura Pecuária e Abastecimento. Instrução Normativa $n^{\circ} 62$ de 26 de agosto de 2003. Oficializa os Métodos Analíticos Oficiais para Análises Microbiológicas para Controle de Produtos de Origem Animal e Água. Diário Oficial da União, Brasília, DF, p. 14, 18 nov. 2003. Seção 1.

CAMPOS, S. G. Monitoramento de aflatoxinas, fungos toxigênicos e níveis de contaminação em matérias-primas e alimentos balanceados. Aflatoxicose natural em cães no Estado do Rio de Janeiro. 2007. Rio de Janeiro, 78 f. Tese (Doutorado em Ciências Veterinárias) - Instituto de Veterinária, Universidade Federal do Rio de Janeiro.

CAMPOS, S.G., CAVAGLIERI, L.R., FERNÁNDEZ JURI, M.G., DALCERO, A.M., KRÜGER, C., KELLER, L.A.M., MAGNOLI, C. AND ROSA, C.A.R.; Mycobiota and aflatoxins in raw materials and pet food in Brazil. Journal of Animal Physiology and Animal Nutrition, 92: 377-383. 2008.
CASE, L. P; DARISTOTLE, L.; HAYEK, M. G.; RAASCH M. F. Canine and Feline Nutrition: a resource for companion animal professionals. 3.ed. Missouri: Mosby Elsevier, 2011. 562p.

FRISVAD, J. C., SAMSON, R. A. Polyphasic taxonomy of Penicillium subgenus Penicillium: A guide to identification of food and air-borne terverticillate Penicillia and their mycotoxins. Studies in Mycology, 2004(49), p.1-173.

$\mathrm{KLICH}, \mathrm{M} . \mathrm{A}$. Identification of common Aspergillus species. Netherlands: Central bureau voor Schinmelcultures, 2002. 116p.

LEUNG, M.C.K.; DÍAZ-LLANO, G.; SMITH, T.K. Mycotoxins in Pet Food: A Review on Worldwide Prevalence and Preventative Strategies. Journal of Agricultural and Food Chemistry, Washington, DC: v.54, n.26, p.9623-9635, 2006.

MAIA P.P., SIQUEIRA, M.E.P.B. Occurrence of aflatoxins B 1, B 2, G 1 and G 2 in some Brazilian pet foods, Food Additives \& Contaminants, 19:12, 1180-1183. 2002.

NELSON P.E., TOUSSOUN T.A., MARASAS W.F.O. Fusarium species: An illustrated manual for identification. The Pennsylvania State University Press, University Park and London, UK, 1983.

PITT J.I., HOCKING A.D. Fungi and Food Spoilage. 2. ed. Blackie Academic Press, London, 1997.

SAMSON R.A., HOEKSTRA E.S., FRISVAD J.C. Introduction to Food- and Airborne Fungi. 7th edition. Centraalbureau voor Schimmelcultures, Utrecht, The Netherlands, 389p, 2004.

WITASZAK, N.; WAŚKIEWICZ, A.; BOCIANOWSKI, J.; STĘPIEŃ, $\nvdash$. Contamination of pet food with mycobiota and Fusarium mycotoxins-focus on dogs and cats. Toxins, v. 12, n. 2, p. 130, 2020. 